\title{
A prediction rule for selective screening of Chlamydia trachomatis infection
}

\author{
H M Götz, J E A M van Bergen, I K Veldhuiizen, J Broer, C J P A Hoebe, J H Richardus
}

Sex Transm Infect 2005;81:24-30. doi: 10.1136/sti.2004.010181

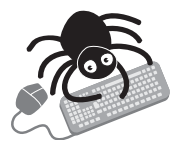

Additional material is available on the website

See end of article for authors' affiliations

.....................

Correspondence to: Ms H M Götz, Municipal Health Service Rotterdam, Department Infectious Diseases, PO Box 70032 3000 LP Rotterdam, the Netherlands; gotzh@ggd.rotterdam.nl

Accepted for publication 24 June 2004

\begin{abstract}
Background: Screening for Chlamydia trachomatis infections is aimed at the reduction of these infections and subsequent complications. Selective screening may increase the cost effectiveness of a screening programme. Few population based systematic screening programmes have been carried out and attempts to validate selective screening criteria have shown poor performance. This study describes the development of a prediction rule for estimating the risk of chlamydial infection as a basis for selective screening.

Methods: A population based chlamydia screening study was performed in the Netherlands by inviting 21000 15-29 year old women and men in urban and rural areas for home based urine testing. Multivariable logistic regression was used to identify risk factors for chlamydial infection among 6303 sexually active participants, and the discriminative ability was measured by the area under the receiver operating characteristic curve (AUC). Internal validity was assessed with bootstrap resampling techniques. Results: The prevalence of C trachomatis (CT) infection was $2.6 \%(95 \% \mathrm{Cl} 2.2$ to 3.2$)$ in women and $2.0 \%$ (95\% Cl 1.4 to 2.7 ) in men. Chlamydial infection was associated with high level of urbanisation, young age, Surinam/Antillian ethnicity, low/intermediate education, multiple lifetime partners, a new contact in the previous two months, no condom use at last sexual contact, and complaints of (post)coital bleeding in women and frequent urination in men. A prediction model with these risk factors showed adequate discriminative ability at internal validation (AUC 0.78).

Conclusion: The prediction rule has the potential to guide individuals in their choice of participation when offered chlamydia screening and is a promising tool for selective CT screening at population level.
\end{abstract}

hlamydia trachomatis (CT) infection is the most prevalent sexually transmitted bacterial infection. It is usually asymptomatic and persistent of nature, and distributed widely in the population, particularly in young people. ${ }^{1}$ The prevalence of chlamydial infection has increased recently in many countries, including the Netherlands. ${ }^{2-5}$ In women, chlamydial infections are a major cause of pelvic inflammatory disease (PID), ectopic pregnancy, tubal infertility, and chronic abdominal pain. ${ }^{1}$ Active case finding and early treatment are crucial strategies to reduce transmission. Systematic screening of women has been shown to reduce the incidence of PID and ectopic pregnancy. ${ }^{67}$ Simple screening strategies (for example, home based) to detect people with an asymptomatic infection has become feasible by improved detection methods of $C$ trachomatis in urine ${ }^{8-11}$ and by the availability of effective single dose treatment. Universal screening is not likely to be cost effective in a population with relatively low chlamydia prevalence. Selective screening, incorporating risk assessment, may increase the cost effectiveness and confronts fewer individuals with an unnecessary test. However, it could lead to an unacceptably high proportion of missed infections. Selective screening criteria for women have been applied in various clinic based, opportunistic chlamydia screening programmes, but their effectiveness has not been evaluated sufficiently. ${ }^{12}{ }^{13}$ Selection criteria for both sexes have been studied recently in population based screening programmes, but these have not led to practical guidelines for selection. ${ }^{14}{ }^{15}$

The objective of our study was firstly to describe risk factors for chlamydial infection among sexually active responders in a large population based chlamydia screening pilot study, including men and women aged 15-29 years from both urban and rural areas in the Netherlands (see p 17, this issue). ${ }^{16}$ Secondly, we wanted to identify a combination of risk factors that discriminated adequately between those who are infected and those who are not.

\section{METHODS}

\section{Study population}

The data of this study were collected in a national probability survey in the Netherlands, which was implemented in four Municipal Public Health Service (MHS) areas and stratified according to area address density (AAD). From September 2002 through March 2003, 12000 women and 9000 men aged 15-29 years received a package by post with a urine sampling kit and a questionnaire concerning demographic data (sex, age, self assigned ethnicity, education), symptoms, history of STI, and sexual behaviour. Urine analysis was done by nucleic acid amplification test (PCR, Roche, Basel, Switzerland). The method of sampling and screening as well as response rates, non-response, and weighted prevalence among all participants are described elsewhere. ${ }^{16}$ The present analysis is restricted to those participants who reported sexual activity in the last six months, because risk factors were only available for this group. The Medical Ethics Committee of the Free University Amsterdam approved the study.

\section{Statistical analysis}

Univariate logistic regression analyses were performed, with self reported characteristics as independent variables and

Abbreviations: AUC, area under the receiver operating characteristic curve; AAD, area address density; MHS, Municipal Public Health Service; PID, pelvic inflammatory disease. 
diagnosis of $C$ trachomatis as the dependent variable. For the odds ratios, 95\% confidence intervals (CI) were calculated. Variables showing an association of $\mathrm{p}<0.2$ were included in the multivariable analysis. Backward stepwise selection was performed with a $\mathrm{p}$ value for the likelihood ratio test $>0.10$ as the criterion for elimination of variables from the model. Interactions between predictors and sex were assessed to study whether effects of predictors were different for men and women. The goodness of fit (reliability) of the model was tested by the Hosmer-Lemeshow statistic. The model's ability to discriminate between participants with or without a chlamydial infection was quantified by using the area under the receiver operating characteristic curve (AUC). AUC values $0.7-0.8$ are considered acceptable, $0.8-0.9$ excellent, and $>0.9$ outstanding. ${ }^{17}$ Calibration was assessed graphically by plotting observed frequencies of chlamydial infection against predicted probabilities.

The performance of screening criteria in a study population, from which the model is developed, is known often to be too optimistic. The internal validity of the regression model was therefore assessed to estimate the performance of the model in new participants, similar to the population used to develop the model. We used bootstrapping techniques: random samples, with replacement, were taken one hundred times from the study population. At each step predictive models were developed, including variable selection. ${ }^{18-20}$ Bootstrapping may help to reduce the bias in the estimated regression coefficients, and give an impression of the discriminative ability in similar participants of screening. The outcome is a correction factor for the AUC, and a shrinkage factor to correct for statistical over-optimism in the regression coefficients and to improve calibration of the model in future participants. ${ }^{18} 2122$ External validity was assessed by leaving out the four MHS in the sample one by one, and fitting regression models, including variable selection, on the remaining data. The discriminative ability of this model was assessed externally on the MHS data not included in the fitting procedure. This procedure replicates the situation in which the prediction model is applied in another MHS region with a population that may to some extent be different.

For the presence or level of each characteristic in the regression model, a score was calculated, based on the regression coefficients with rounding to simplify the calculation in practice. These scores are an immediate reflection of the logarithm of the odds ratios. ${ }^{23}$ For each individual these scores were added into a sum score, on the basis of which a regression formula was calculated, taking into account the shrinkage factor derived from the bootstrap procedure. An estimate of the probability for chlamydial infection can be calculated through the regression formula

$$
\mathrm{p}(\mathrm{Ct})=1 / 1+\exp ^{(-\mathrm{LPS})}
$$

where LPS is linear predictor for score. All possible sum scores and their corresponding predicted probabilities of chlamydial infection were combined in a graph with 95\% CIs of the predicted probabilities. The confidence interval was calculated, based on a covariance matrix. The average standard error (SE) of the rounded linear predictor values was used to calculate the $95 \%$ CIs of the predicted probabilities $\left(1 / 1+\mathrm{e}^{-(\mathrm{LPS}+/-1.96 \times \mathrm{SE})}\right) .^{24}$

For consecutive cut offs of the sum scores, sensitivity, specificity, fraction positive, and positive predictive values were calculated. Statistical analysis was done with SPSS statistical software version 10.0 (SPSS Inc, Chicago, IL, USA) and with the Design Library for S-plus 2000 (Insightful Inc, Seattle, WA, USA).

\section{RESULTS}

Prevalence among sexually active participants

The participation rate was $41 \%$ and the prevalence of chlamydial infection among sexually active responders was $2.3 \%(160 / 7005) .{ }^{16}$ Among the 6303 participants who reported being sexually active in the previous six months, 153 tested positive $(2.4 \%$ (95\% CI 2.1 to 2.8$)$ ). The prevalence was $2.6 \%$ (95\% CI 2.2 to 3.2 ) in women and $2.0 \%$ (95\% CI 1.4 to 2.7 ) in men.

\section{Performance of predictive model and development of prediction score}

Multivariable logistic regression analysis showed that chlamydial infection was associated with high urbanisation, young age, ethnicity (Surinamese/Antillian), low/intermediate education, multiple lifetime partners, a new contact in the previous two months, no condom use at last sexual contact, and complaints of (post)coital bleeding in women and frequent urination in men (table 1). The only statistically significant interaction term in the model was sex and the number of lifetime partners.

The Hosmer-Lemeshow goodness of fit test had a p value of 0.12 , indicating adequate goodness of fit. The model discriminated well between participants who were and were not infected by C trachomatis, with an AUC of 0.81 (95\% CI 0.77 to 0.84 ). Internal validation showed optimism in the AUC of 0.03 , resulting in a correction of the AUC from 0.81 to 0.78 . In the external validation similar sets of predictors were selected. When tested in each separate MHS, the AUC varied from 0.74 to 0.80 . When leaving out the MHS representing mainly $\mathrm{AAD} 1$ and 2, ethnicity did not remain in the model developed from the three other MHS areas. This is related to the finding that the majority of non-Dutch participants in our study population were from this particular MHS area.

Table 2 shows the scores of the prediction rule. The sum score for a 16 year old Surinam woman living in an moderately urbanised area, with intermediate education, three lifetime partners, and a new contact in the previous two months, no postcoital bleeding, and condom use during last intercourse, is $11(1+2+2+2+3+1+0+0)$. The predicted probability of chlamydial infection for this participant is $11 \%$ (95\% CI 6 to 20) (fig 1). The discrimination on the basis of the sum score was as good as the discrimination of the original model (AUC $0.80(0.76-0.84)$ ).

Plots of observed frequency of infection against predicted probabilities showed that calibration of both the model and the score were good for the predicted probabilities up to $10 \%$ (see http://www.stijournal.com/supplemental for fig 2).

\section{Application of the prediction rule}

The probability of chlamydial infection according to the prediction rule can be used for selection in chlamydia screening. Table 3 shows the results for different cut off levels of sum scores. The first row gives the scenario for performing screening in our whole study population and therefore identifying all patients with a $C$ trachomatis infection (sensitivity $100 \%$ ). When screening is performed in all sexually active participants with a sum score $\geqslant 8$, the number to be screened in our study population would be reduced to $33 \%$. However, $21 \%$ of the cases would then be missed (sensitivity $79 \%$ ). The expected prevalence in the screened group would be $5.7 \%$, in contrast to $2.3 \%$ on average. By lowering the cut off from a sum score from $\geqslant 8$ to $\geqslant 6$, one would have to screen an additional $30 \%$ of the population to find $93 \%$ of the cases. By doing this, the percentage of unnecessarily screened people in the study population would increase from $32 \%$ to $62 \%$. 
Table 1 Prevalence of $C$ trachomatis infection and risk factors among participants sexually active in the previous six months in a screening programme

\begin{tabular}{|c|c|c|c|c|c|c|c|c|c|}
\hline & \multirow[b]{2}{*}{ n } & \multirow[b]{2}{*}{$\mathrm{N}$} & \multirow[b]{2}{*}{$\%$} & \multicolumn{3}{|c|}{ Univariable } & \multicolumn{3}{|c|}{ Multivariable } \\
\hline & & & & OR & $95 \% \mathrm{Cl}$ & $p L R$ & OR & $95 \% \mathrm{Cl}$ & $\mathrm{p} L \mathrm{R}$ \\
\hline \multicolumn{10}{|l|}{ Sex } \\
\hline Men & 39 & 1999 & 2.0 & 1.0 & & & & & \\
\hline Women & 114 & 4304 & 2.6 & 1.4 & $0.9-2.0$ & 0.088 & & - & \\
\hline Age group (years) & & & & & & 0.030 & & & 0.084 \\
\hline $15-19$ & 45 & 1440 & 3.1 & 1.2 & $0.8-1.8$ & & 1.4 & $0.9-2.1$ & \\
\hline $20-24$ & 43 & 2359 & 1.8 & 0.7 & $0.5-1.0$ & & 0.8 & $0.5-1.2$ & \\
\hline $25-29$ & 65 & 2504 & 2.6 & 1.0 & & & 1.0 & & \\
\hline$A A D^{*}$ & & & & & & $<0.001$ & & & $<0.001$ \\
\hline Very high urban (AAD 1) & 57 & 1344 & 4.2 & 5.8 & $3.0-11.1$ & & 3.9 & $1.9-7.7$ & \\
\hline $\begin{array}{l}\text { Low/moderate/high } \\
\text { urban (AAD 2-4) }\end{array}$ & 85 & 3507 & 2.4 & 3.3 & $1.7-6.1$ & & 2.6 & $1.4-4.9$ & \\
\hline Rural (AAD 5) & 11 & 1452 & 0.8 & 1.0 & & & 1.0 & & \\
\hline Ethnicity & & & & & & $<0.001$ & & & 0.005 \\
\hline Dutch & 125 & 5802 & 2.2 & 1.0 & & & 1.0 & & \\
\hline Surinamese/Antillian & 15 & 116 & 12.9 & 6.7 & $3.8-11.9$ & & 3.2 & $1.7-6.2$ & \\
\hline Other & 12 & 370 & 3.2 & 1.5 & $0.8-2.8$ & & 1.0 & $0.5-1.9$ & \\
\hline Educationt & & & & & & $<0.001$ & & & $<0.001$ \\
\hline Low & 55 & 1508 & 3.6 & 2.8 & $1.8-4.4$ & & 3.0 & $1.8-4.9$ & \\
\hline Intermediate & 66 & 2567 & 2.6 & 1.9 & $1.2-3.0$ & & 2.2 & $1.4-3.6$ & \\
\hline High & 29 & 2151 & 1.3 & 1.0 & & & 1.0 & & \\
\hline \multicolumn{10}{|l|}{$\begin{array}{l}\text { Women's complaints, } \\
\text { previous } 4 \text { weeks }\end{array}$} \\
\hline (Post)coital bleeding & & & & & & 0.004 & & & 0.053 \\
\hline Yes & 12 & 184 & 6.5 & 2.7 & $1.5-5.1$ & & 2.0 & $1.0-4.0$ & \\
\hline No & 102 & 4120 & 2.5 & 1.0 & & & 1.0 & & \\
\hline Intermenstrual bleeding & & & & & & 0.002 & & & \\
\hline Yes & 18 & 321 & 5.6 & 2.4 & $1.4-4.0$ & & & & \\
\hline No & 96 & 3983 & 2.4 & 1.0 & & & & & \\
\hline Abnormal vaginal & & & & & & 0.025 & & & \\
\hline $\begin{array}{l}\text { discharge } \\
\text { Yes }\end{array}$ & 29 & 741 & 3.9 & 1.7 & $1.1-2.6$ & & & & \\
\hline No & 85 & 3563 & 2.4 & 1.0 & & & & & \\
\hline Painful urination & & & & & & 0.228 & & & \\
\hline Yes & 14 & 385 & 3.6 & 1.4 & $0.8-2.5$ & & & & \\
\hline No & 100 & 3919 & 2.6 & 1.0 & & & & & \\
\hline Frequent urination & & & & & & 0.014 & & & \\
\hline Yes & 21 & 465 & 4.5 & 1.9 & $1.2-3.1$ & & & & \\
\hline No & 93 & 3839 & 2.4 & 1.0 & & & & & \\
\hline Lower abdominal pain & & & & & & 0.025 & & & \\
\hline Yes & 29 & 741 & 3.9 & 1.7 & $1.1-2.6$ & & & & \\
\hline No & 85 & 3563 & 2.4 & 1.0 & & & & & \\
\hline \multicolumn{10}{|l|}{ Men's complaints, previous } \\
\hline Frequent urination & & & & & & 0.016 & & & 0.051 \\
\hline Yes & 6 & 102 & 5.9 & 3.5 & $1.4-8.6$ & & 2.8 & $1.1-7.2$ & \\
\hline No & 33 & 1897 & 1.7 & 1.0 & & & 1.0 & & \\
\hline Painful urination & & & & & & 0.060 & & & \\
\hline Yes & 4 & 71 & 5.6 & 3.2 & $1.1-9.3$ & & & & \\
\hline No & 35 & 1928 & 1.8 & 1.0 & & & & & \\
\hline Urethral discharge & & & & & & 0.103 & & & \\
\hline Yes & 2 & 26 & 7.7 & 4.4 & $1.0-19.1$ & & & & \\
\hline No & 37 & 1973 & 1.9 & 1.0 & & & & & \\
\hline Age at first sex (years) & & & & & & $<0.001$ & & & \\
\hline$\leqslant 15$ & 61 & 1413 & 4.3 & 3.0 & $2.0-4.6$ & & & & \\
\hline $16-17$ & 57 & 2433 & 2.3 & 1.6 & $1.0-2.5$ & & & & \\
\hline$\geqslant 18$ & 32 & 2315 & 1.4 & 1.0 & & & & & \\
\hline Lifetime partners (women) & & & & & & $<0.001$ & & & $<0.001$ \\
\hline 1 & 8 & 1633 & 0.5 & 1.0 & & & 1.0 & & \\
\hline $2-5$ & 55 & 2045 & 2.7 & 5.6 & $2.7-11.8$ & & 4.6 & $2.4-8.9$ & \\
\hline$\geqslant 6$ & 49 & 597 & 8.2 & 18.2 & $8.5-38.6$ & & 13.5 & $6.8-27.1$ & \\
\hline Lifetime partners (men) & & & & & & $<0.001$ & & & $<0.001$ \\
\hline 1 & 4 & 567 & 0.7 & 1.0 & & & 1.0 & & \\
\hline $2-5$ & 13 & 919 & 1.4 & 2.0 & $0.7-6.2$ & & 2.6 & $1.1-5.9$ & \\
\hline$\geqslant 6$ & 20 & 491 & 4.1 & 6.0 & $2.0-17.6$ & & 5.3 & $2.4-11.7$ & \\
\hline Partners in previous 6 months & & & & & & $<0.001$ & & & \\
\hline 1 & 103 & 5509 & 1.9 & 1.0 & & & & & \\
\hline $2-5$ & 43 & 717 & 6.0 & 3.3 & $2.3-4.8$ & & & & \\
\hline$\geqslant 6$ & 7 & 77 & 9.1 & 5.2 & $2.4-11.7$ & & & & \\
\hline Sexual preference & & & & & & 0.194 & & & \\
\hline Heterosexual & 148 & 6179 & 2.4 & 1.0 & & & & & \\
\hline Homo/bisexual & 5 & 110 & 4.5 & 1.9 & $0.8-4.8$ & & & & \\
\hline New contact in previous & & & & & & $<0.001$ & & & 0.004 \\
\hline 2 months & & & & & & & & & \\
\hline Yes & 47 & 765 & 6.1 & 3.3 & $2.3-4.8$ & & 1.9 & $1.2-2.8$ & \\
\hline No & 106 & 5515 & 1.9 & 1.0 & & & 1.0 & & \\
\hline
\end{tabular}




\begin{tabular}{|c|c|c|c|c|c|c|c|c|c|}
\hline & \multirow[b]{2}{*}{$\mathbf{n}$} & \multirow[b]{2}{*}{$\mathrm{N}$} & \multirow[b]{2}{*}{$\%$} & \multicolumn{3}{|c|}{ Univariable } & \multicolumn{3}{|c|}{ Multivariable } \\
\hline & & & & OR & $95 \% \mathrm{Cl}$ & $p L R$ & OR & $95 \% \mathrm{Cl}$ & p LR \\
\hline $\begin{array}{l}\text { Condom use at last sexual } \\
\text { contact }\end{array}$ & & & & & & 0.204 & & & 0.029 \\
\hline Yes & 26 & 1330 & 2.0 & 1.0 & & & 1.0 & & \\
\hline No & 126 & 4954 & 2.5 & 1.3 & $0.9-2.0$ & & 1.6 & $1.0-2.6$ & \\
\hline $\begin{array}{l}\text { Contraception at last } \\
\text { sexual contact }\end{array}$ & & & & & & 0.169 & & & \\
\hline Yes & 124 & 5312 & 2.3 & 1.0 & & & & & \\
\hline No & 28 & 895 & 3.1 & 1.4 & $0.9-2.0$ & & & & \\
\hline History of self reported STI & & & & & & 0.005 & & & \\
\hline Yes & 18 & 371 & 4.9 & 2.2 & $1.3-3.7$ & & & & \\
\hline No & 132 & 5894 & 2.2 & 1.0 & & & & & \\
\hline \multicolumn{10}{|c|}{$\begin{array}{l}\left.\left.\text { *AAD 1, very high urban ( }>2500 \text { addresses } / \mathrm{km}^{2}\right) \text {; AAD 2, high urban (1500-2500 addresses } / \mathrm{km}^{2}\right) \text {; AAD 3, } \\
\left.\text { moderate urban }\left(1000-1500 \text { addresses } / \mathrm{km}^{2}\right) ; A A D \text { 4, low urban (500-1000 addresses } / \mathrm{km}^{2}\right) ; A A D \text {, rural } \\
\left(<500 \text { addresses } / \mathrm{km}^{2}\right) \text {. } \\
\text { †Low: primary school, lower vocational, or lower general secondary education; intermediate: intermediate } \\
\text { vocational education, intermediate, or higher general secondary education; high: higher vocational education or } \\
\text { university education. }\end{array}$} \\
\hline
\end{tabular}

\section{DISCUSSION}

In this large, population based study demographic, behavioural, clinical, and geographic risk factors in 15-29 year old women and men were identified from which a prediction rule for $C$ trachomatis infection could be developed. This study has led to a promising tool for selective chlamydia screening at population level.

\section{Risk factors identified}

Young age predicted chlamydial infection independently, as has been reported by others. ${ }^{25}$ Surinamese/Antillian ethnicity proved to be a strong predictive factor, confirming previous findings in Amsterdam. ${ }^{15} 26$ Contrary to other population based studies, we observed low and intermediate education to be predictive for chlamydial infection in both sexes. ${ }^{15} 2527$ Ethnicity and level of education as a risk factor may merely reflect risky sexual behaviour. Nevertheless, we assume the independent character of these variables to reflect risks involved in sexual partner choice: in case of unsafe sex, acquisition of a chlamydial infection is related to chlamydia

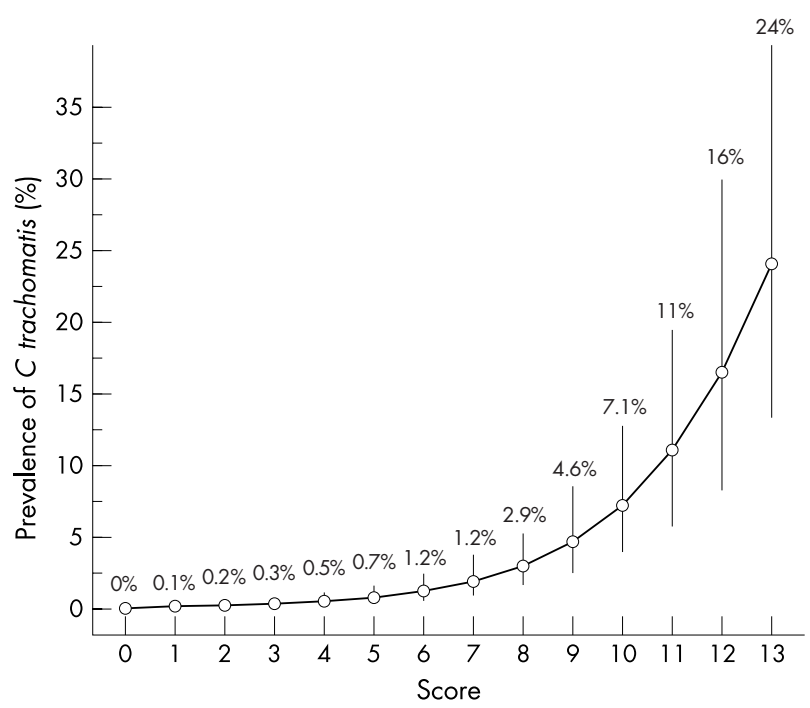

Figure 1 Predicted probability of $C$ trachomatis infection as a function of the sum score. The sum score (horizontal axis) was derived from the prediction rule (table 2). On the vertical axis the predicted prevalence of $\mathrm{C}$ trachomatis is depicted. Vertical lines represent $95 \% \mathrm{Cls}$. Since only eight participants had a sum score of 14 (predicted prevalence 33\% (18-55), this score is not shown. prevalence background rates within particular sexual networks. Area address density, a geographic factor, remained an independent risk factor for chlamydial infection. As expected, people living in very highly urbanised areas (AAD 1) have the highest risk. However, living in less urbanised areas (AAD 2-4) was also associated independently with chlamydia infection. This finding may be important for decision making regarding future screening programmes. Incorporating $\mathrm{AAD}$ score points in selective screening decisions takes care of variations in prevalence within and between regions. ${ }^{28}$ Although symptoms of frequent urination and (post)coital bleeding in the previous four weeks symptoms were relatively infrequent and have probably not led to healthcare seeking behaviour, they predicted chlamydial infection. The number of lifetime partners was a strong independent predictor for chlamydial infection, but with a difference in the strength of association for men and women. Other indicators of sexual behaviour that proved predictive

Table 2 Prediction rule for quantifying the probability of C trachomatis infection

\begin{tabular}{|c|c|c|}
\hline \multirow[b]{2}{*}{ Predictor } & \multicolumn{2}{|l|}{ Score } \\
\hline & Women & Men \\
\hline \multicolumn{3}{|l|}{ Age group (years) } \\
\hline $15-19$ & 1 & 1 \\
\hline $20-24$ & 0 & 0 \\
\hline $25-29$ & 0 & 0 \\
\hline \multicolumn{3}{|l|}{$A A D$} \\
\hline Rural (AAD 5) & 0 & 0 \\
\hline Low/moderate/high urban (AAD 2-4) & 2 & 2 \\
\hline Very high urban (AAD 1) & 3 & 3 \\
\hline \multicolumn{3}{|l|}{ Ethnicity } \\
\hline Dutch or other & 0 & 0 \\
\hline Surinam or Antillian & 2 & 2 \\
\hline \multicolumn{3}{|l|}{ Education } \\
\hline Low or intermediate & 2 & 2 \\
\hline High & 0 & 0 \\
\hline Urogenital symptoms* & 1 & 2 \\
\hline \multicolumn{3}{|l|}{ Lifetime sexual partners } \\
\hline 1 & 0 & 0 \\
\hline $2-5$ & 3 & 2 \\
\hline$\geqslant 6$ & 5 & 3 \\
\hline New partner previous 2 months & 1 & 1 \\
\hline No condom last sexual contact & 1 & 1 \\
\hline \multicolumn{3}{|c|}{$\begin{array}{l}\text { *Women, (post)coital bleeding previous } 4 \text { weeks; men, frequent urinatio } \\
\text { previous } 4 \text { weeks. } \\
\text { An estimate of the probability of } C \text { trachomatis infection can be } \\
\text { calculated using the formula } p(C t)=1 / 1+\exp (- \text { LPS), where } \\
\text { LPS }=-7.26+0.47 \times \text { score. }\end{array}$} \\
\hline
\end{tabular}


Table 3 Implications of using the prediction rule for screening for $C$ trachomatis

\begin{tabular}{lcccc}
\hline $\begin{array}{l}\text { Cut off sum } \\
\text { score* }\end{array}$ & Sensitivity† & Specificitył & $\begin{array}{l}\text { Fraction } \\
\text { positiveq }\end{array}$ & PPV§ \\
\hline$\geqslant 0$ & $100.0 \%$ & $0.0 \%$ & $100.0 \%$ & $2.3 \%$ \\
$\geqslant 1$ & $100.0 \%$ & $0.5 \%$ & $99.5 \%$ & $2.4 \%$ \\
$\geqslant 2$ & $100.0 \%$ & $2.4 \%$ & $97.7 \%$ & $2.4 \%$ \\
$\geqslant 3$ & $100.0 \%$ & $4.6 \%$ & $95.5 \%$ & $2.5 \%$ \\
$\geqslant 4$ & $99.3 \%$ & $14.4 \%$ & $85.9 \%$ & $2.7 \%$ \\
$\geqslant 5$ & $94.4 \%$ & $23.0 \%$ & $77.4 \%$ & $2.9 \%$ \\
$\geqslant 6$ & $93.1 \%$ & $38.3 \%$ & $62.4 \%$ & $3.5 \%$ \\
$\geqslant 7$ & $86.8 \%$ & $56.0 \%$ & $45.0 \%$ & $4.5 \%$ \\
$\geqslant 8$ & $79.2 \%$ & $68.4 \%$ & $32.7 \%$ & $5.7 \%$ \\
$\geqslant 9$ & $59.0 \%$ & $83.2 \%$ & $17.8 \%$ & $7.8 \%$ \\
$\geqslant 10$ & $41.7 \%$ & $92.2 \%$ & $8.6 \%$ & $11.4 \%$ \\
$\geqslant 11$ & $27.8 \%$ & $96.8 \%$ & $3.7 \%$ & $17.5 \%$ \\
$\geqslant 12$ & $11.8 \%$ & $98.9 \%$ & $1.4 \%$ & $20.5 \%$ \\
$\geqslant 13$ & $4.2 \%$ & $99.8 \%$ & $0.3 \%$ & $31.6 \%$ \\
$\geqslant 14$ & $1.4 \%$ & $99.9 \%$ & $0.1 \%$ & $25.0 \%$ \\
\hline
\end{tabular}

*Selection criterion for screening.

†Percentage of detected chlamydial infections among our study participants when screening under the given selection.

$\ddagger$ Percentage of chlamydia negative participants who would not be screened justly.

- Percentage of the total population that is eligible for screening under the given selection.

§Prevalence in the screened population (predictive value of selection criterion).

were a new contact in the previous two months, and unsafe sex at last contact. This finding is in line with systematic and opportunistic screening programmes in Women. ${ }^{152527} 29$ Young age at first sex and multiple partners in the previous six months were significant univariable risk factors but did not remain in the model, which can be explained by correlation with lifetime partners.

\section{Methodological considerations}

An important objective of this study was to develop a prediction model, based on risk factors that discriminate adequately between those who are infected with $C$ trachomatis and those who are not. Logistic regression is the most appropriate statistical technique to achieve this goal. Decisions about selection in screening could also be based on a decision tree type model, but in comparative studies the performance of classification and regression trees was not better than classical regression methods. ${ }^{30-32}$ We therefore preferred logistic regression for our statistical analysis.

In the first instance we had constructed separate models for females and males, but because of low numbers the separate male model was not very robust. Also, most risk factors had very similar effects in both sexes (see http:// www.stijournal.com/supplemental for tables 4 and 5). To enhance power, we combined males and females in one model. Interaction between sex and all other determinants for chlamydial infection were tested extensively and the only interaction present was between sex and the number of lifetime partners. This effect was included in the combined model, resulting in different scores for this factor for females and males. The strength of the combined model is illustrated for the variable ethnicity. This variable disappeared in the male model because of a lack of power, causing our separate male model to be awkward to work with in practice. In a combined model, effects in males can be influenced by effects in females, but as the ratio of females to males is approximately 2:1, we consider the balance between the sexes in our combined model to be acceptable.

Performance of screening criteria in a study population is often too optimistic, and is seldom evaluated in another population. This is illustrated by the disappointing performance of selective screening criteria for asymptomatic chlamydial infection in an inner city population ${ }^{33}$ and in different clinics. ${ }^{12}{ }^{13}{ }^{15}$ Whereas those studies used one part of their data as the development sample and another part to validate their screening criteria, we used bootstrap resampling, which is statistically more efficient. ${ }^{20}$ Bootstrapping may help to improve the calibration of predictions, and give an impression of the discriminative ability in similar populations. In our test for generalisability (external validation), the model showed acceptable performance for the various MHS regions when using the three other MHS regions for developing the model. The lower AUCs at external validation can be explained to some extent by the sampling method, which was designed to obtain a representative sample for the Netherlands. Not all AAD categories were present in the respective MHS samples. Although our internal and external validation procedures showed satisfactory results in general, further validation is necessary before the prediction rule can be applied reliably in practice. Validation could be done on existing datasets that used similar definition of the predictor variables and for presence of chlamydial infection.

A limitation of our data is that we asked for details of sexual behaviour only in people who had been sexually active in the previous six months-as this had consequences for partner tracing. Therefore, multivariable analysis could only be done for $90 \%$ (6303) of all sexually active participants and the derived score can be applied only to those who have been sexually active in the previous six months. The prevalence among those ever sexually active, but not in the previous six months, was $1 \%$ (7/681). Assuming no recent partner change and condom use at last contact (both score zero), allowed us to estimate the sum score with the available data. We then predicted chlamydial infection among those ever sexually active (through the formula in table 2). The AUC of the prediction in all ever sexually active participants was 0.80 (0.76-0.83) compared with the AUC of $0.81(0.77-0.84)$ in the participants who were sexually active recently. This result provides an argument that in practice the prediction rule can be applied to all sexually active people. Another possible limitation of our study is the fact that the relatively low response rate, especially among men, non-Dutch, and those with intermediate education might affect our results due to selection bias. $^{16}$

\section{Application of the prediction rule for screening}

Our sum score allows for prediction of chlamydial infection in individuals as well as applications for cut off values for decisions in screening programmes at population level. Usually a fixed choice of risk factors is used as selection criterion for screening. Instead, our sum score consists of varying combinations of risk factors, mirroring the probability of infection. Not every person has to fulfil a fixed combination of criteria for screening. The sum score can (potentially) guide individuals in their decision to accept the screening test. As we have shown, the predictive value of the screening criterion based on a selection of a score $\geqslant 8$ would be $5.7 \%$. Hence $94.3 \%$ of the eligible population screened would not have chlamydia. However, the absolute number of people screened unnecessarily is lower than when screening without selection. The issue of the most efficient cut off level depends on both costs and priorities-either finding most cases or minimising unnecessarily screened people. In population based screening-whether in a specified age group in the whole population or in a restricted geographic area-a prediction rule can be applied to motivate people with a score above a certain level to participate. For instance, an invitation letter for screening could include a simple questionnaire for calculating a personal score, together with a request form for a test kit, or a referral to a website. In 


\section{Key messages}

- Risk factors for chlamydia can be used for targeted screening and thus may improve the efficiency of screening in population based programmes.

- Regression modelling including a validation process can be used to derive a score, which can be applied at an individual level to determine whether screening should be offered.

- In a population based study in the Netherlands, prevalence of $C$ trachomatis was $2.6 \%$ in women and $2.0 \%$ in men. Predictors for chlamydial infection were high urbanisation, young age, ethnicity, low or intermediate education, multiple lifetime partners, a new contact in the previous two months, no condom use at last sexual contact, and complaints of (post)coital bleeding in women and frequent urination in men.

- In the population studied, the prediction score had adequate discriminative ability, but because such a score developed for one population tends to perform less well in other populations, it should be subject to external validation.

opportunistic screening, the clinician can inquire about the predictive criteria.

In conclusion, this study found demographic, geographic, and behavioural characteristics as well as urogenital symptoms as indicators for chlamydial infections in 15-29 year old women and men in a population based study. Our study indicates that one could consider screening all young women and/or men universally, whether systematic or opportunistic, in regions or settings with high prevalence, or apply the predictive score in regions or settings with lower prevalence. The prediction rule for chlamydial infection opens new avenues for risk assessment in population based screening and possibly in opportunistic screening as well.

\section{ACKNOWLEDGEMENTS}

G Borsboom (statistician, Department of Public Health, Erasmus MC, Rotterdam) assisted in developing the model. The scientific advisory board consisted of: Professor P J E Bindels (Department of General Practice, Academic Medical Centre, University of Amsterdam), A J P Boeke, PhD (Department of General Practice, VU University Medical Centre, Amsterdam), Professor J D F Habbema (Department of Public Health, Erasmus MC, Rotterdam), J A R van den Hoek, PhD (Municipal Public Health Service Amsterdam), S A Morré, PhD (Laboratory of Immunogenetics, VU University Medical Centre, Amsterdam), and L Jacobi MSc (Groningen).

\section{CONTRIBUTORS}

HG wrote the first draft and finalised the report. JVB was project leader of PILOT CT. HG, JVB, IV, JB, CH, JR, AC, FDG, DVS, and MV have contributed to the study design and protocol, collected and interpreted data, critically reviewed the draft, and were all involved in the final report. Statistical analysis was performed by IV, HG, JR, and ES.

\section{Authors' affiliations \\ H M Götz, I K Veldhuijzen, J H Richardus, Municipal Public Health Service Rotterdam, the Netherlands \\ J E A M van Bergen, D T van Schaik, STI AIDS (SOA AIDS Nederland) Amsterdam, the Netherlands \\ J Broer, Municipal Public Health Service Groningen, the Netherlands C J P A Hoebe, Municipal Public Health Service Eastern South Limburg, the Netherlands \\ J H Richardus, E W Steyerberg, Department of Public Health, Erasmus MC, University Medical Center Rotterdam, the Netherlands}

M J C Verhooren, Municipal Public Health Service 'Hart voor Brabant', the Netherlands

The PILOT CT study group are: JEAM van Bergen, J Broer, AJJ Coenen, HM Götz, F de Groot, CJPA Hoebe, JH Richardus, DT van Schaik, EW Steyerberg, IK Veldhuiizen, MJC Verhooren.

This research has been financed by a grant from Zorg Onderzoek Nederland, which has no commercial interests and had no role in study design, organisation of the study, and/or writing of the report.

Conflict of interest: none declared

\section{REFERENCES}

1 Stamm W. Chlamydia trachomatis infections of the adult. In: Sexually transmitted diseases, In: Holmes K, Sparling P, Mardh PA, eds. New York: McGraw-Hill, 1999:407-23.

2 Gotz H, Lindback J, Ripa T, et al. Is the increase in notifications of Chlamydia trachomatis infections in Sweden the result of changes in prevalence, sampling frequency or diagnostic methods? Scand J Infect Dis 2002;34:28-34.

3 van de Laar MJW, van Veen MG, Coenen AJJ. Registration of STI and HIV consultations at Regional Community Health Services in the Netherlands: Annual Report 2002. RIVM report 441500015/2003. Bilthoven, 2003 (in Dutch).

4 van der Snoek EM, Götz HM, Mulder PG, et al. Prevalence of STD and HIV infections among attenders of the Erasmus MC STD clinic, Rotterdam, the Netherlands, during the years 1996 to 2000 . Int J STD AIDS 2003;14:119-24.

5 Wilson J S, Honey E, Templeton A, et al. A systematic review of the prevalence of Chlamydia trachomatis among European women. Hum Reprod Update 2002;8:385-94.

6 Egger M, Low N, Smith GD, et al. Screening for chlamydial infections and the risk of ectopic pregnancy in a county in Sweden: ecological analysis. BMJ 1998;316:1776-80

7 Scholes D, Stergachis A, Heidrich FE, et al. Prevention of pelvic inflammatory disease by screening for cervical chlamydial infection. N Engl J Med 1996;334:1362-6.

8 Andersen B, Ostergaard L, Moller JK, et al. Home sampling versus conventional contact tracing for detecting Chlamydia trachomatis infection in male partners of infected women: randomised study. BMJ 1998;316:350-1.

9 Morre SA, van Valkengoed IG, de Jong A, et al. Mailed, home-obtained urine specimens: a reliable screening approach for detecting asymptomatic Chlamydia trachomatis infections. J Clin Microbiol 1999;37:976-80.

10 Morre SA, Van Valkengoed IG, Moes RM, et al. Determination of Chlamydia trachomatis prevalence in an asymptomatic screening population: performances of the LCx and COBAS Amplicor tests with urine specimens. $J$ Clin Microbiol 1999;37:3092-6.

11 Ostergaard L, Andersen B, Olesen F, et al. Efficacy of home sampling for screening of Chlamydia trachomatis: randomised study. BMJ 1998;317:26-7.

12 Marrazzo JM, Fine D, Celum CL, et al. Selective screening for chlamydial infection in women: a comparison of three sets of criteria. Fam Plann Perspect 1997;29:158-62.

13 Miller WC, Hoffman IF, Owen-O'Dowd J, et al. Selective screening for chlamydial infection: which criteria to use? Am J Prev Med 2000;18:115-22.

14 Andersen B, van Valkengoed I, Olesen F, et al. Value of self-reportable screening criteria to identify asymptomatic individuals in the general population for urogential Chlamydia trachomatis infection screening. Clin Infect Dis 2003;36:837-44.

15 van Valkengoed IG, Morre SA, van den Brule AJ, et al. Low diagnostic accuracy of selective screening criteria for asymptomatic Chlamydia trachomatis infections in the general population. Sex Transm Infect 2000;76:375-80

16 Van Bergen JEAM, Gotz HM, Richardus JH, et al. Prevalence of urogenital Chlamydia trachomatis increases significantly with level of urbanisation and suggests targeted screening approaches: results from the first national population-based study in the Netherlands. Sex Transm Infect 2005;81:17-23.

17 Hosmer D, Lemeshow S. Assessing the fit of the model. In: Applied logistic regression. Wiley J. New York: 1999;(1 1):135-75.

18 Harrell FE, Lee KL, Mark DB. Multivariable prognostic models: issues in developing models, evaluating assumptions and adequacy, and measuring and reducing errors. Stat Med 1996;15:361-87.

19 Steyerberg EW, Bleeker SE, Moll HA, et al. Internal and external validation of predictive models: a simulation study of bias and precision in small samples. $J$ Clin Epidemiol 2003;56:441-7.

20 Steyerberg EW, Harrell FE, Borsboom GJ, et al. Internal validation of predictive models: efficiency of some procedures for logistic regression analysis. J Clin Epidemiol 2001;54:774-81.

21 Harrell F. Regression coefficients and scoring rules. J Clin Epidemiol 1996;49:819.

22 Van Houwelingen JC, Le Cessie S. Predictive value of statistical models. Stat Med 1990;9:1303-25.

23 Moons KG, Harrell FE, Steyerberg EW. Should scoring rules be based on odds ratios or regression coefficients? J Clin Epidemiol 2002;55:1054-5.

24 Krijnen $P$, van Jaarsveld BC, Steyerberg EW, et al. A clinical prediction rule for renal artery stenosis. Ann Intern Med 1998;129:705-11.

25 Fenton KA, Korovessis C, Johnson AM, et al. Sexual behaviour in Britain: reported sexually transmitted infections and prevalent genital Chlamydia trachomatis infection. Lancet 2001;358:1851-4. 
26 van den Hoek JA, Mulder-Folkerts DK, Coutinho RA, et al. Opportunistische screening op genitale infecties met Chlamydia trachomatis onder de seksueel actieve bevolking in Amsterdam. I. Meer dan 90\% deelname en bijna 5\% prevalentie. Ned Tijdschr Geneeskd 1999;143:668-72.

27 Verhoeven V, Avonts D, Meheus A, et al. Chlamydial infection: an accurate model for opportunistic screening in general practice. Sex Transm Infect 2003;79:313-17

28 Miller WC. Screening for chlamydial infection. A model program based on prevalence. Sex Transm Dis 1998;25:201-10.

29 Paukku M, Kilpikari R, Puolakkainen $M$, et al. Criteria for selective screening for Chlamydia trachomatis. Sex Transm Dis 2003;30:120-3.
30 Ennis M, Hinton G, Naylor D, et al. A comparison of statistical learning methods on the Gusto database. Stat Med 1998;17:2501-8.

31 Marshall RJ. The use of classification and regression trees in clinical epidemiology. J Clin Epidemiol 2001;54:603-9.

32 van Dijk MR, Steyerberg EW, Stenning SP, et al. Survival of patients with nonseminomatous germ cell cancer: a review of the IGCC classification by Cox regression and recursive partitioning. Br J Cancer 2004;90:1176-83.

33 van Valkengoed IG, Boeke AJ, Morre SA, et al. Disappointing performance of literature-derived selective screening criteria for asymptomatic Chlamydia trachomatis infection in an inner-city population. Sex Transm Dis 2000;27:504-7.

\section{CHESTER CHRONICLES}

\section{Art attack}

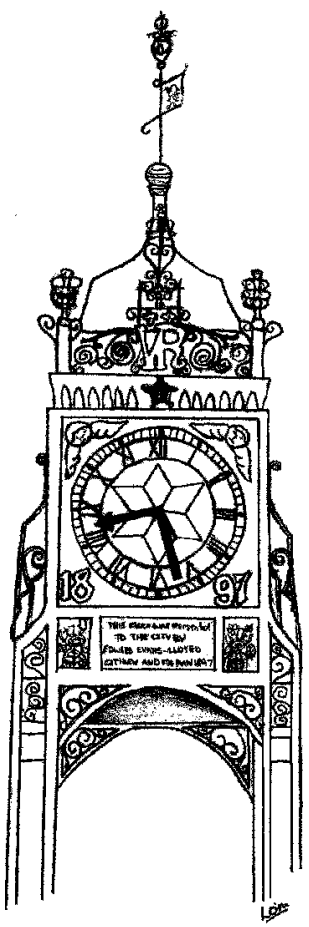

EASTGATE CLOCK, CHESTER
Ahoa! Where's my pictures gone?" I stare dumfounded at dusty blank areas on the wall of the corridor into the Sexual Health Clinic-somebody's nicked my pictures. I remembered painfully carrying them one by one from the car park from the boot of my own car with great difficulty. They were at least $4^{\prime} 0^{\prime \prime} \times 4^{\prime} 0^{\prime \prime}$ heavy pine frames, and now some scurrilous scally has made off with them. It was now 7.30 on a Tuesday evening and none of the other staff who had left earlier had noticed anything missing. I told Security, who simply said to phone the police in the morning and report it as an incident. This wasn't good enough. I wanted justice. The next morning, I took the extreme liberty of abusing the hospital email system by sending an email to all Countess of Chester Hospital staff. This has often been done in the past by people saying "car lights left on," etc, etc, so I felt justified under these extenuating circumstances in sending out the following email:

"Some low life made off with two large $4^{\prime} 0^{\prime \prime} \times 4^{\prime} 0^{\prime \prime}$ pictures from the corridor of GenitoUrinary Medicine yesterday evening at about 6-6.30 pm. Surely, somebody must have seen something. I hope the individual concerned develops an incurable STD-any info to Security or Dr O'Mahony."

Within minutes I was emailed back with perfect information regarding the description of the individual and the timing of the theft, allowing a specific check of security cameras to locate the event! See, I knew those Morse videos were educational.

The Cheshire Constabulary also duly arrived and I proudly expounded on the investigative acumen of Detective Inspector C O'Mahony who was now within an ace of recovery of the goods and catching the culprit. However, the officer was appalled when reading my email to come across the injudicious wish of an incurable STD. Not since my last appraisal have I been so thoroughly ridiculed and chastised, as he pointed out to me that any documentation in a case must be supplied to the defence also, and they would have taken me to the cleaners over such an ill advised comment. Imagine the local newspaper (the real "Chester Chronicle") with a headline from court "Leading Hospital Consultant Threatens Incurable STD on Innocent..."

Luckily, the police didn't have to take the matter further, as the Hospital Security Staff interviewed a patient who led them to where the pictures had been stashed for later collection and disposal. Suffice it to say, my pictures are back, my rashness is reprimanded, and the case is closed.

Incidentally, a third picture was also found in the stash and no one has the faintest idea where it's from. It's a weird, ugly picture, and looks to be by some guy called Edward or Edvard? Munch and there are some Belgian Museum markings on the frame. If no one claims it soon, we'll just have to chuck it out, as I couldn't possibly contemplate putting it up in the clinic. Any takers? 